\title{
Elementos histórico-culturais para o ensino dos instrumentos ópticos ${ }^{+*}$
}

\author{
Marlon C. Alcantaral \\ Departamento de Educação e Ciências \\ Instituto Federal de Educação, Ciência e Tecnologia do Sudeste de Minas Gerais \\ Juiz de Fora - MG \\ Marco Braga ${ }^{2}$ \\ Centro Federal de Educação Tecnológica Celso Suckow da Fonseca \\ Rio de Janeiro - RJ
}

\section{Resumo}

Neste trabalho, apresentaremos uma proposta para o ensino dos instrumentos ópticos a partir de uma abordagem contextual da História das Ciências. Para isso, utilizaremos uma Rede de Relações Sociais que tem Constantijn Huygens (1596-1687) como centro (hub). A partir de fontes primárias e de outros documentos que tratam da cultura holandesa no século XVII, buscaremos mostrar como essa rede, composta por cientistas, pintores e filósofos, ligada a fatores como a religião e o comércio, pode nos oferecer uma visão interdisciplinar e complexa sobre o advento dos instrumentos ópticos. A visão contextual desse período histórico poderá fornecer subsídios para a construção de um currículo interdisciplinar a partir dos instrumentos ópticos.

Palavras-chave: História da Ciência; Interdisciplinaridade; Redes Históricas; Natureza da Ciência; Ciência e Arte.

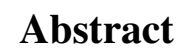

In this paper we presented a proposal for the teaching of optical instruments with a historical-cultural approach. For this, we used a network of

\footnotetext{
${ }^{+}$Historical and cultural elements for teaching of optical instruments

* Recebido: abril de 2016.

Aceito: outubro de 2016.

1 E-mail: marlon.alcantara@ifsudestemg.edu.br

2 E-mail: marcobraga.pq@gmail.com
} 
social relations that has Constantijn Huygens (1596-1687) as its center (hub). Through primary sources and other documents dealing with Dutch culture in the seventeenth century, we showed how this network of scientists, artists, and philosophers combined to factors such as religion and trade, can offer an interdisciplinary and complex view of the advent of optical instruments. The contextual view of this historical period may provide subsidies for the construction of an interdisciplinary curriculum from optical instruments.

Keywords: History of Science; Interdisciplinarity; Historical Networks; Nature of Science; Science and Art.

\section{Introdução}

Buscar um ensino que trabalhe a Ciência de uma forma integral, mostrando alguns aspectos relacionados à construção do pensamento científico, e estando em conformidade com as demandas institucionais, vem sendo um desafio bastante discutido em periódicos nacionais e internacionais (MATTHEWS, 1992; GUERRA; REIS; BRAGA, 2004; HÖTTECKE; SILVA, 2011; ALLCHIN, 2011; FORATO; PIETROCOLA; MARTINS, 2011; HENKE; HÖTTECKE, 2015). Quando olhamos para os instrumentos educacionais, tais como livros didáticos e plataformas digitais, são raras as vezes que conseguimos encontrar a História, Filosofia e Sociologia da Ciência (HFSC) sendo abordadas de uma forma que permita ao aluno perceber a Ciência como um empreendimento complexo. Em geral, são dadas informações rápidas e, muitas vezes, caricatas do trabalho científico. Se nos voltarmos para a formação de professores, sobretudo de Física, encontraremos cursos que apresentam a História da Física como uma disciplina independente - algo estanque, que não interage com os conteúdos das disciplinas básicas. Raros são os cursos em que as disciplinas de Física já são apresentadas a partir de um olhar histórico-filosófico. Como os professores tendem a ensinar como aprenderam, eles acabam pensando na HFSC como um adereço, uma curiosidade que necessita ser incorporada à sua prática como um complemento daquilo que acreditam ser o verdadeiro ensino de Física.

Essa pouca participação da HFSC nos cursos de formação de professores, seja como conteúdo a ser estudado ou mesmo como metodologia para o ensino de Física, tem-se mostrado como uma das barreiras para se introduzir a HFSC na Educação Básica (PERON; ALCANTARA; JARDIM, 2015).

Outro ponto que vem sendo um obstáculo à introdução da HFSC na Educação Básica são os livros didáticos (REIS et al, 2001, p. 370-371). Na grande maioria dos livros didáticos, a HFSC aparece em boxes, à parte do texto principal, em geral tratando, basicamente, de um resumo da vida do cientista. A relativa dificuldade de se encontrar textos bem construídos nos livros didáticos é justificada por Whitaker (apud TAVARES; PRESTES, 2012), o qual afirma 
que o principal objetivo desses manuais não é fornecer relatos históricos e, por esse motivo, existe pouco espaço para eles. Contudo as autoras afirmam que:

Uma opção melhor, talvez, fosse a de reduzir o número de episódios históricos abordados para que se ganhasse mais espaço para apresentações contextualizadas. Dessa forma, o livro didático atenderia ao que se preconiza atualmente no ensino de ciências, apresentando o conhecimento científico associado a seu contexto de produção. Por sua vez, os professores de ensino médio contariam com materiais históricos consonantes com a historiografia renovada da história da ciência, que incorpora uma dentre as várias possibilidades pelas quais se alcança o ensino contextual de ciências. (TAVARES; PRESTES, 2012, p. 41)

Este artigo visa dar subsídios para a construção de materiais didáticos de HFSC a partir de uma visão contextual. Para tanto, será utilizada uma ferramenta que vem sendo usada em diversas áreas do conhecimento e que percebemos ser bastante útil em um estudo de HFSC que parta dessa visão mais abrangente: Análise de Redes Sociais (ARS).

O campo de estudo da ARS vem-se desenvolvendo desde o nascimento da teoria dos grafos, desenvolvida por Euler a partir de um problema da ponte de Königsberg (BARABASI, 2009, p. 8-11). Esse campo da Ciência foi-se modelando com a colaboração de físicos, biólogos, engenheiros, programadores e, atualmente, oferece um excelente parâmetro para entendermos melhor como são disseminadas as informações, tanto em uma rede virtual, com base na web, quanto em uma rede real (WATTS, 2009; BARABASI, 2009; LEMIEUX; OUIMET, 2012).

Procuramos, neste artigo, aplicar ferramentas de Análise De Redes Sociais ao campo histórico, visando compreender como diversos atores humanos e não humanos (LATOUR, 1997), como cientistas, filósofos, artistas e instrumentos científicos, relacionaram-se em um determinado período histórico. Essa metodologia foi utlizada para compreender aspectos relativos à construção do conhecimento de forma complexa, não ficando restrita apenas ao campo científico.

Como o estudo versa sobre instrumentos ópticos, decidimos começar pela Holanda do século XVI e XVII. Estabelecemos os personagens mais significativos e buscamos suas relações. A primeira surpresa veio com o surgimento de cientistas, filósofos e artistas de grande importância individual, que, normalmente, são apresentados nos livros didáticos dessa forma. Quando vistos dentro de uma rede, eles passam a ser percebidos como parte de uma importante construção coletiva. Esse fato quebrava, de imediato, com a velha visão do intelectual genial e solitário que deu uma contribuição gigantesca para a Ciência, fruto de uma inspiração quase divina.

Algumas fontes foram de fundamental importância para o estabelecimento incial dessa rede. Assim, deparamo-nos com um acervo de cartas trocadas no século XVII, através plataforma ePistolarium ${ }^{3}$. No início do mundo moderno, as cartas foram, de longe, o mais

\footnotetext{
3 Plataforma on-line em que podem ser encontradas cerca de 20.000 cartas da República Holandesa do século XVII, uma parceria entre o Huygens ing, Universidade de Utrech, Descartes Centre, DANS, Universidade de
} 
importante meio de comunicação entre estudiosos (VAN DEN HEUVEL, 2015, p. 98). Dessa forma, compomos nossa pesquisa histórica baseada no banco de dados da plataforma ePistolarium, nos livros e artigos sobre as histórias de vida de cada um dos personagens, bem como com os caminhos epistemológicos percorridos pelos mesmos.

Percebemos que esse material era de grande importância para os professores que desejavam ensinar Física a partir de uma visão interdisciplinar, em diálogo com os outros docentes que ministram disciplinas aparentemente distantes para os alunos nas escolas, como Filosofia, História, Sociologia, Religião e Artes. Acreditamos que as ferramentas da ARS, bem como todo material catalogado e produzido pelos grupos que trabalham com Redes Históricas, podem contribuir, de forma significativa, para esse objetivo.

A partir dessa constatação, decidimos escrever materiais didáticos com base nessas redes de conhecimento e aplicá-los nas escolas. Não pretendemos, entretanto, neste artigo, mostrar os resultados obtidos nessas aplicações. Desejamos apresentar um recorte histórico que nos permita visualizar a disseminação e o desenvolvimento dos instrumentos ópticos na Holanda, a partir de uma visão interdisciplinar e complexa da Ciência, amparada por ferramentas utilizadas na ARS.

\section{Uma luz para a construção de uma História Cultural: o conhecimento em rede}

O estabelecimento de uma nova forma de conhecer o século XVII remonta um assunto polêmico e complicado: a construção de uma visão de mundo. Podemos afirmar que visão de mundo é a forma pela qual interagimos e interpretamos os fenômenos naturais e sociais, sendo que essas interpretações servem não só para compreender, como também para transformar (ALCANTARA; BRAGA, 2010, p. 2). As relações que envolvem essa construção são, de certa forma, complexas e dinâmicas. Sabemos, também, que essas relações são mediadas pela cultura, em que estão presentes crenças, valores e até o continuísmo de pensamento, que nos conforta e coloca-nos em um "porto seguro". Enfim, são as bases que modelam nosso olhar da realidade e todos os nossos atos, regendo a interação homem-universo (MATTHEWS, 2009).

Essa visão de mundo está diretamente arraigada com todos os nossos modelos mentais. Dentro dessas visões de mundo, estão contidas, ainda, as visões de natureza ou até mesmo visões de Ciência (ABRANTES, 1998).

A visão mecanicista de natureza veio se impondo desde o século XVII, nos estudos científicos, e consolidou-se como uma forma segura e linear de estudos em quase todos os campos da Ciência. Posteriormente, com o advento do Positivismo, a Ciência passou a ser referenciada a partir de suas bases metodológicas e do olhar para a natureza como uma grande máquina, em que não cabiam referências metafísicas. Vale lembrar que não existiu apenas um mecanicismo, mas vários. No mecanicismo cartesiano, podia-se dizer que a máquina do mundo era

Amsterdam e Koninklijke Bibliotheek. Disponível em: <http://ckcc.huygens.knaw.nl/epistolarium/>. Acesso em: 10 out. 2016. 
composta de diversos sistemas, em que um não se comunicava com os outros, criando-se uma noção de realidade autônoma (ALCANTARA, 2011). Esse posicionamento demarca a Ciência não como o mundo das argumentações, mas como um campo arbitrário que destrói qualquer necessidade de argumentar coletivamente (DEMO, 2008). Essa visão de natureza e de ciência foi assimilada por todos, principalmente a partir do século XIX com a instituição de uma Educação em Ciências formal nas escolas (BRAGA, 2000). Esse modelo, criado no século XIX, cristalizou-se no tempo. A escola concreta que temos hoje é herdeira desse modelo. Seu eixo central é a apresentação de disciplinas sequenciadas que não dialogam. Mesmo as científicas mantêm-se isoladas em nichos que, muitas vezes, não existem na vida real. Esse tipo de divisão tem dado aos alunos uma visão bastante deturpada da Natureza da Ciência, tanto no que tange ao seu caráter interno (intracientífico) como no externo, que envolve as relações das Ciências com diversas outras áreas.

$\mathrm{O}$ isolamento e a linearidade dos diversos tipos de conhecimento vêm sendo questionados por vários autores (MORIN, 1993; SNOW, 1995; MARIOTTI, 2007; DEMO, 2008; ALMEIDA, 2010), que defendem uma nova postura diante do conhecer. Essa herança de matriz cartesiana, em que o todo é a soma das partes, propôs uma eficiente ferramenta de análise, cabendo ao aluno a tarefa de fazer a síntese. Essa separação, contudo, vem causando desconforto, hoje, em diversos setores da sociedade, visto que se percebe uma imensa dicotomia entre o mundo que a escola apresenta e o mundo complexo em que vivemos.

O Pensamento Complexo, nascido na Teoria da Informação, nos anos 1960 do século XX, foi absorvido mais recentemente pelas Ciências Sociais. Nele, o todo é percebido como sendo diferente da soma das partes, apontando para a construção de uma visão do objeto de conhecimento que não seja fragmentada, mas desenvolvida a partir de uma rede de conhecimentos (MORIN, 2005).

Importa ressaltar que, mesmo dentro de um panorama complexo, nada é puramente linear, podendo apenas apresentar faces lineares. A linearidade é algo também importante, pois é a partir dos episódios lineares que conseguimos interagir com o todo em uma visão mais sistêmica. Dessa forma, alargar as bases do conhecimento, fugir da verticalização e da especialização, é um papel fundamental para o entendimento de um dado fenômeno, seja ele social ou científico. Dividir o conhecimento em partes pode ser perigoso, porquanto, essa visão de conhecimento fragmentado pode, na verdade, criar visões irreais das Ciências ou do próprio mundo em que vivemos. Podemos afirmar que a Física Clássica, nascida no século XVII, apoiase em três pilares, a ordem, a separabilidade e a lógica, sendo que esta correlaciona os fatos. Por meio da filosofia positivista, a verificação ou confirmação revelariam a realidade objetiva, independente dos observadores (DEMO, 2008). Na Física Clássica, a separabilidade entre o observador e sua observação adquiriu valor absoluto. Esse determinismo e essa visão de ordem passaram por muitos abalos a partir das contribuições filosóficas trazidas pela Física Moderna, com questões postas por estudos no campo da Termodinâmica e com o advento do Princípio da Complementaridade (PRIGOGINE; STENGERES, 1984). 
O pensamento complexo trabalha com o conjunto de fatores que vão além da soma das partes. Mas, mesmo nesse panorama, deve-se não somente religar as partes, mas também encontrar e adotar uma postura com relação à incerteza. Vale lembrar que conhecimento consistente é aquele capaz de contextualizar, isto é, religar, globalizar (MORIN, 1998).

Esse sentimento de complexidade visto dentro de um regime de solidariedade e fraternidade, de um lado, não pode ser interligado a partir de elos puramente mecânicos. Mas, de outro, a complexidade pode ser também um risco, uma vez que um sistema altamente complexo possui muitas liberdades, o que acaba levando-o a uma desintegração enquanto sistema. A dinâmica indica o processo, que, a par de componentes formalizáveis e controláveis, detém outros não formalizáveis. Dinâmica que se pode controlar não é propriamente dinâmica, pois trabalha dentro de fatores previsíveis. A rota propriamente criativa é aquela que avança no imprevisível, está além do que podemos vislumbrar no momento, ultrapassa o horizonte do conhecimento (DEMO, 2008).

Visando trabalhar os instrumentos ópticos a partir do ponto de uma abordagem histórico-filosófica, vimo-nos diante de um desafio: entender o porquê do surgimento de tantos aparatos ópticos no século XVII, sobretudo sua vasta disseminação na Holanda. Para isso, procuramos evidências que extravasavam os livros técnicos ou mesmo os livros de Ciências. Buscamos, nos relatos a respeito das pinturas holandesas, uma confirmação sobre a utilização de aparatos ópticos nas pinturas (ALPERS, 1999; HOCKNEY, 2001; STEADMAN, 2001). Não obstante, deparamo-nos com a estreita relação entre o pintor Johannes Vermeer (1632-1675) e o microscopista Anton van Leeuwenhoek (1632-1723). A partir desse ponto, surgiu a necessidade de abrir mais nosso plano de pesquisa e, desse modo, chegamos a Constantijn Huygens (15961687) e a Royal Society de Londres, ponto no qual nos vimos obrigados a aprofundar nossa pesquisa procurando fontes primárias que pudessem nos apresentar um panorama mais abrangente sobre a difusão dos instrumentos ópticos na Holanda do século XVII.

Assim, devido a uma série de fatores presentes nas "partes", a via que tomamos para que chegássemos ao "todo" ou a uma fração deste que nos permitisse entender o advento das lentes a partir de uma perspectiva histórico-cultural foi a montagem de uma Rede de Relações Sociais (RRS). Como este estudo visa apresentar as relações entre personagens e suas obras para subsidiar o ensino, não nos apegaremos a aspectos teóricos que regem a Análise de Relações Sociais. Acreditamos que esses termos já se encontram bastante difundidos do ponto de vista teórico nos trabalhos de Watts (2009), Barabasi (2009), Christakis e Fowler (2010), Lemieux e Ouimet (2012).

\section{A Holanda e seu século de ouro}

Até a metade do século XVI, as 17 províncias dos Países Baixos pertenciam ao Império espanhol e estavam submetidas ao reinado de Carlos V, Imperador sagrado de Roma e Rei da Espanha. Nesse período, o Imperador abdicou de seu trono em favor de seu filho Felipe II, que passou a ditar novos caminhos para todo o Reino. 
Durante o século $\mathrm{XV}$, os Países Baixos haviam se tornado uma região próspera. Com a finalidade de financiar novas guerras, Felipe II começou a cobrar altos impostos, medida que levou a população a certa insatisfação. Além dos impostos, diversos comerciantes holandeses começaram a ficar contrariados, devido às muitas investidas militares espanholas contra seus parceiros comerciais. Tal fato ocasionava perdas econômicas às províncias. Mas havia ainda outra questão que afetava, ideologicamente, os holandeses, a religiosa. A imposição de um catolicismo conservador sobre uma maioria protestante fez com que aos elementos comerciais e financeiros se unissem divergências de cunho religioso no repúdio ao domínio espanhol (LEE, 1994, p. 16).

A difusão do calvinismo pela Holanda teve um significado importante, uma vez que esse pregava virtudes como a clareza, a modéstia e o trabalho duro. O dinheiro e a prosperidade não eram condenados como na ideologia católica, ao contrário, significavam bênçãos. Esses princípios estavam em pleno acordo com os objetivos comerciais dos holandeses, que começaram a buscar, além do lucro, seus direitos, liberdade e tolerância religiosa (ELLIOTT, 2000).

Em 1566, um pequeno motim de calvinistas ocorreu do lado de fora da catedral de Antuérpia (hoje pertencente à Bélgica), dando origem a um confronto direto entre os interesses calvinistas e os interesses espanhóis, que estavam diretamente ligados ao catolicismo. Em maio de 1568 , tem início a revolta holandesa contra os espanhóis. Liderada por Guilherme I de Orange, essa batalha ficou mais conhecida como Guerra dos 80 anos. A partir desse momento, começa a luta pela independência. As províncias reformistas se tornaram independentes em 1579. O senso de nacionalidade fortemente desenvolvido foi o resultado e não a causa da revolta contra a Espanha (SCHAMA, 1992, p. 64). Somente em 1648, a Espanha reconheceu a independência dos holandeses. A liberdade política atingida acabou incitando outras áreas, por meio da abertura a novas ideias culturais e científicas (ARAÚJO, 2005), fato que será de grande importância para este estudo.

A partir da Independência, a Holanda passou a ser um refúgio de liberdade do pensamento europeu. Nas sete províncias que se libertaram, apesar de calvinistas, procurou-se manter uma tolerância de pensamento (BURKE, 2003, p. 148-149) bem diferente de áreas que estavam sob influência da Inquisição. Diversos filósofos buscaram refúgio na Holanda. Baruch Spinoza (1632-1677), apesar de já ter nascido na Holanda, descendia de uma família judia portuguesa, que fugiu junto com milhares de outros judeus da perseguição religiosa em seu país de origem. John Locke (1632-1704) viveu na Holanda entre 1683 e 1689, devido à perseguição católica que sofreu na Inglaterra. Descartes (1596-1650) passou diversos e longos períodos de sua vida em várias cidades holandesas. Algumas de suas obras mais importantes foram editadas primeiramente lá. Além desses, Leibniz (1646-1716) visitou a região várias vezes.

Essa estrutura comercial e religiosa pode também ter contribuído para o aparecimento de vários pintores, já que a diferença entre pobres e ricos não era tão grande como em outros países da Europa. Esses pintores procuraram retratar a realidade, não se apegando a imagens 
idealizadas de mundo, como as pinturas italianas da mesma época. Esse tipo de pintura, hoje, é conhecida como pintura de gênero (ARAÚJO, 2005).

Os anos compreendidos entre 1570 e 1670 podem ser considerados como Era de Ouro da Holanda, pois, além de se tornar uma grande potência marítima e comercial da Europa, tornou-se, também, uma grande potência cultural em diversos campos (SCHAMA, 1992, p. 282).

\section{O estabelecimento de uma Rede de Conhecimentos}

O conhecimento produzido na Holanda, ao longo do século XVII, foi vasto e altamente diversificado, não se caracterizando por uma única área do saber. No recorte que fizemos para esta pesquisa, percebemos que há diversos personagens ligados à Física, à Biologia, à Filosofia e às Artes Plásticas, os quais formaram uma rede de influências, troca de informações, novas ideias e conhecimentos (Fig. 1).

Constantijn Huygens (1596-1687) foi um dos atores centrais dessa rede. Com interesse em Artes, Filosofia e Ciência Experimental, ele foi um incentivador de diversos cientistas, filósofos e artistas. Entre eles, está seu filho, o físico Christiaan Huygens (1629-1695), o microscopista Anton van Leeuwenhoek (1632-1723), os filósofos Baruch Spinoza (1632-1677) e René Descartes (1596-1650), além dos pintores Rembrandt (1606-1669) e Johannes Vermeer (16321675).

Constantijn Huygens era filho do secretário da primeira província da nova República da Holanda e sucedeu seu pai nesse cargo (VERMIJ, 2010, p. 77). Combinou o serviço ao Estado e à ortodoxia religiosa com uma variedade de aptidões artísticas e intelectuais (SCHAMA, 1992; ALPERS, 1999; JARDINE, 2008). Ressaltamos que sua biblioteca era quase a metade do tamanho da que possuía o Rei da França. Era um amante das Artes e um dos responsáveis por ser intermediário entre artistas e nobres compradores. Entre os artistas, destacam-se Peter Paul Rubens (1577-1640), Anton van Dyck (1599-1641), Mierevelt (1566-1641). Além disso, foi um dos maiores divulgadores das pinturas de Rembrandt (LEERINTVELD; PLOEG, 2013, p. 86-89).

Constantijn não era um homem comum. Alguns chegaram a afirmar, como Johan Huizinga, historiador holandês, que, para entender a Holanda, era preciso entender entendê-lo (ALPERS, 1999, p. 47), porquanto, ele foi o precursor, o motivador e, até mesmo em alguns casos, financiador dessa geração. 


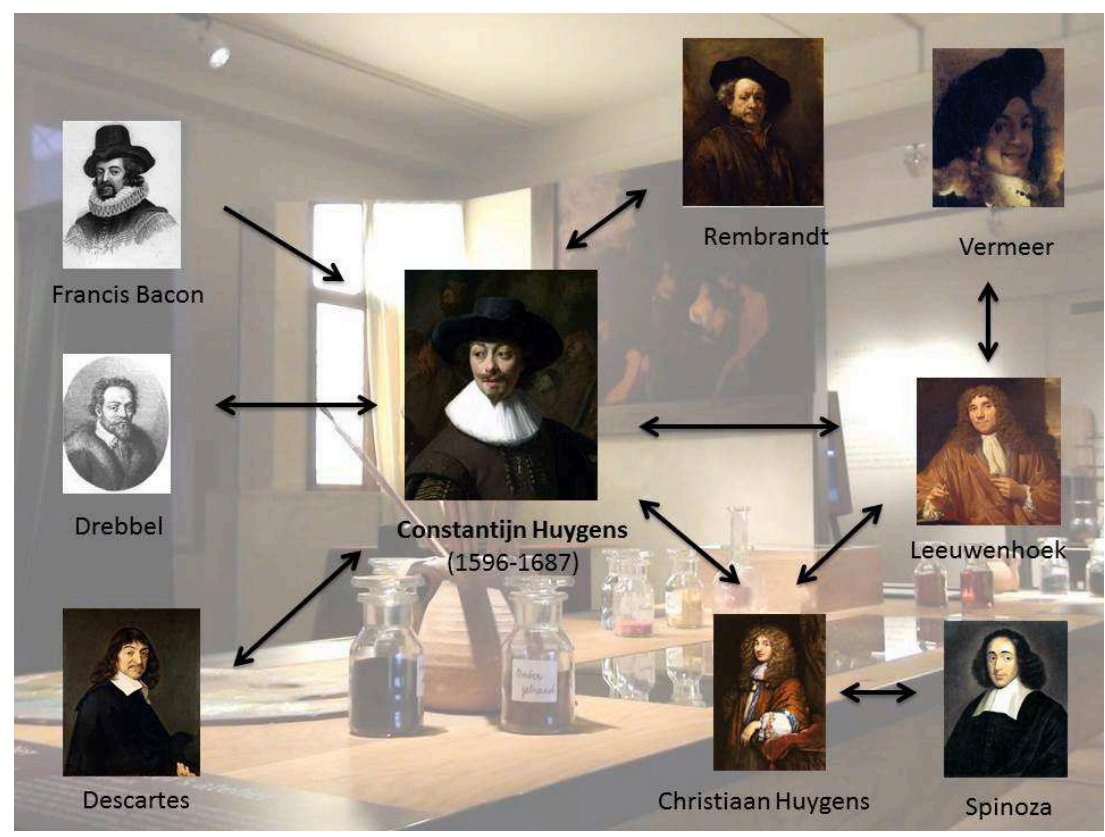

Fig.1 - Rede de Relações Sociais. Fonte: Rede organizada pelos próprios autores.

Na plataforma ePistolarium, podemos ter acesso à rede de Constantijn Huygens na qual são disponibilizadas 7.500 cartas entre enviadas e recebidas por ele, entre os anos de 1608 e 1622. Na Fig. 2, podemos ter uma dimensão dessa Rede de Relacionamentos a partir das cartas.

Constantijn deixou, em sua autobiografia, um grande elogio a Francis Bacon, a quem disse venerar com respeito, vindo a conhecê-lo, pessoalmente, em uma de suas viagens a Inglaterra (JARDINE, 2008; SNYDER, 2015). Era amigo de Cornelius Drebbel (1572-1633), inventor holandês que vivia na Inglaterra, de forte ligação com a pintura holandesa, pois estudou em Haarlem e se casou com a irmã de Hendrick Goltzius (1558-1617), artista de uma geração anterior. A admiração de Constantijn por Drebbel tem seu ponto alto quando o segundo apresenta um microscópio ao primeiro, que olha através dele e se espanta dizendo ter visto um novo mundo por meio daquele instrumento óptico. As lentes o fascinaram. Como não havia estudado pintura, Constantijn procura um artista para representar o que vira no microscópio, pressupondo que a pintura se prestava a uma função descritiva (ALPERS, 1999). O empirismo britânico será fonte de inspiração à pintura holandesa, que se caracterizou por retratar aquilo que os olhos revelavam e não o que a imaginação poderia construir (ALPERS, 1999, p. 88).

Em uma carta de 13 de abril de 1622, Constantijn, em Londres, relata a seu filho Christiaan, em Haia, sua surpresa ao olhar a câmara obscura de Drebbel:

[...] Eu tenho na minha casa o outro instrumento de Drebbel, que decerto faz efeitos admiráveis na pintura de reflexão em um quarto escuro; não me é possível vos descrever essa beleza em palavras; toda pintura está morta à apreensão, já que é aqui a vida em si mesma, ou alguma coisa mais elevada, se a palavra não lhe falta, uma vez 
que a figura e o contorno e os movimentos se encontram naturalmente e de um modo grandemente prazeroso. Os Degheyns se comprazem maravilhosamente, mas nosso primo Carel se enfurecerá [... $]^{4}$ (Tradução livre dos autores).

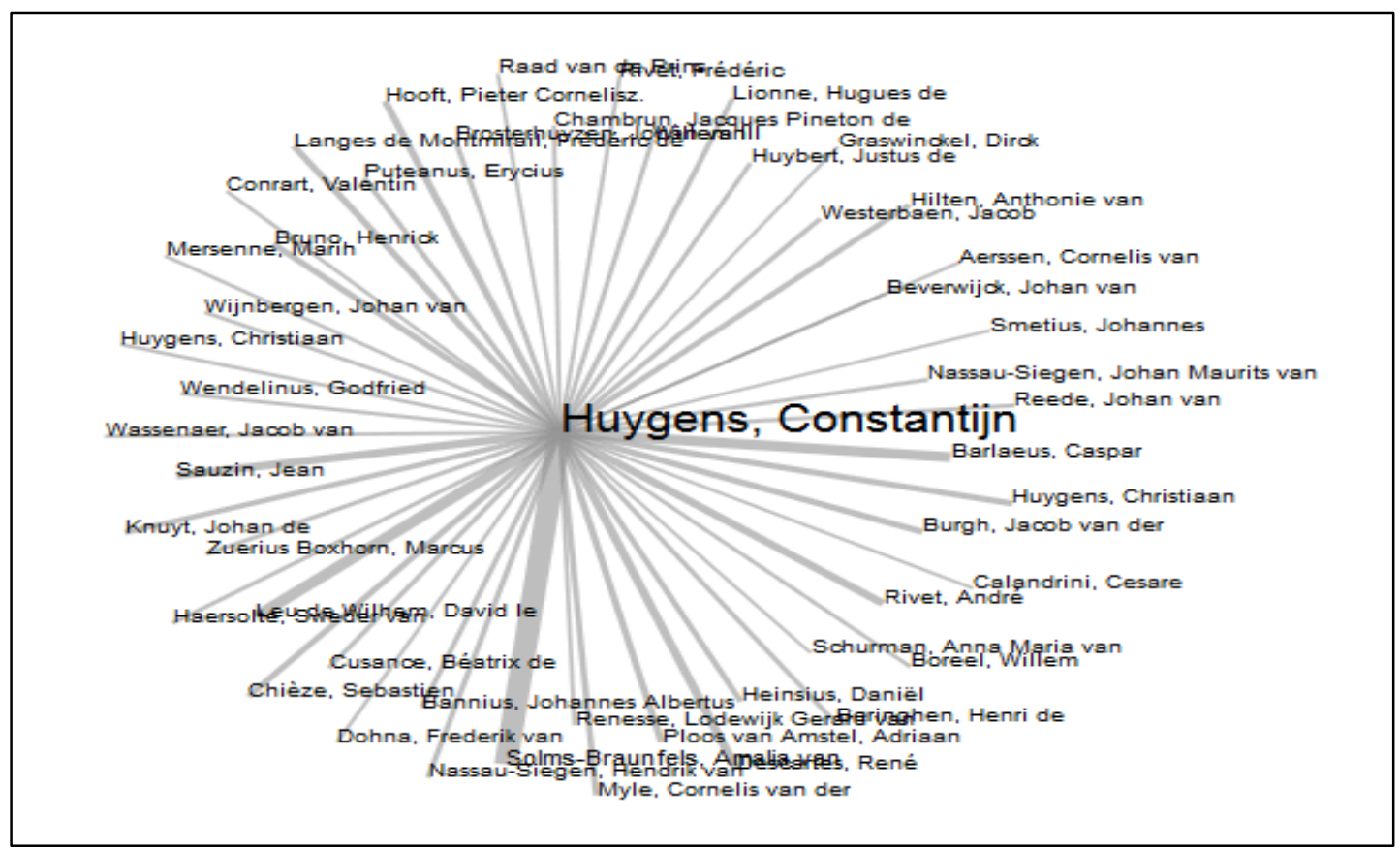

Fig. 2 -Rede de Relacionamentos de Constantijn Huygens por cartas trocadas. Fonte: Plataforma ePistolarium. Disponível em: <http://ckcc.huygens.knaw.nl/epistolarium/>. Acesso em: 16 out. 2015.

Após visitar a Inglaterra diversas vezes, Constantijn levou para a Holanda as lentes e o conhecimento da prática observacional e experimental dos ingleses. As lentes chegaram através da câmara escura. $\mathrm{O}$ nome desse instrumento científico provém do italiano e significa "quarto escuro", sendo o equipamento mencionado por várias pessoas, tal como Giovanni Battista della Porta (1535-1615). O termo "câmara obscura", como "Darkchamber", também foi mencionado por Kepler (1571-1630) em seu livro Dioptrice, de 1611 (SNYDER, 2015, p.130).

No livro The origins of the telescope, de Van Helden et al. (2010), há um relato da importância de Constantijn Huygens no advento das lentes na Holanda, assim como nos estudos sobre ótica:

Constantijn Huygens (1596-1687), secretário do Stadtholder e intermediário de destaque na vida cultural da República Holandesa, estava muito interessado em óptica. Ele tinha incitado Jacobus Golius (1596-1667) para investigar refração, aparentemente com algum sucesso. Ele também organizou o pessoal e os meios para o projeto de moagem de lentes esféricas de Descartes. [...], claro que a busca da óptica foi

\footnotetext{
4 Trecho da carta de Constantijn Huygens para Christiaan Huygens, 13 de abril de 1622. Disponível em: <http://ckcc.huygens.knaw.nl/epistolarium/letter.html?id=huyg001/0143>. Acesso em: 6 abr. 2016.
} 
fortemente estimulada na Holanda na década de 1630 (DIJKSTERHUIS, 2010, p. 264. Tradução livre dos autores).

Ao ser aperfeiçoada com o uso de lentes com excelente qualidade, as quais eram fabricadas pelos holandeses, a câmara escura fascinou não só Constantijn, como também grande parte da Europa, tornando-se um instrumento fundamental tanto na Ciência como na Arte do século XVII.

\section{As lentes nas Ciências}

A construção de instrumentos ópticos para uso na Ciência e na Arte pode ter tido sua popularização no Renascimento italiano, momento em que instrumentos foram utilizados em obras de engenharia, investidas militares e até mesmo na pintura, como é o caso do topógrafo (CAMEROTA, 2009). Outro aparato óptico que se utilizou das lentes e que foi bastante difundido foi a câmara escura de orifício. Nesse período, conhecida como Cinquecento, a câmara escura de Giacomo della Porta (1485-1555) começa a ganhar suas lentes. O desenvolvimento e a fabricação dos instrumentos com lentes têm seu ponto máximo na Itália, quando Galileu, em 1609, aperfeiçoa a luneta holandesa e, assim, observa a Lua.

Nesse momento, a fabricação de lentes era uma das atividades econômicas de grande importância na Holanda. Vários cientistas, filósofos e artistas da época trabalharam como polidores de lentes.

Christiaan Huygens era filho de Constantijn e dedicou-se à Física, à Astronomia e à Ótica. Não diferente do pai, Christiaan também tinha uma vasta Rede de Relacionamentos como, por exemplo, Giovanni Domenico Cassini (1625-1712), Jacobus Golius (1596-1667), Gottfried Leibniz (1646-1716) e Baruch Spinoza, além de um longo período de trabalhos realizados em conjunto com seu irmão Constantijn Jr. (1628-1697), principalmente com atividades relacionadas ao polimento de lentes, desenvolvimento de telescópios e microscópios entre 1670 e 1680. Cabe ressaltar que Constantijn Jr. foi secretário de William III de Orange (1650-1702) durante a Revolução Gloriosa, na Inglaterra (JARDINE, 2008, p. 93).

Na plataforma ePistolarium, podemos ter acesso a três cartas do ano de 1666, em que Spinoza escreve a Christiaan fazendo referências a assuntos diversos. Na carta datada de maio de 1666, percebemos que Spinoza descreve, com bastante propriedade, alguns fenômenos da ótica como a refração, além do ajuste e tipo da lente convexo-côncava e abertura de tubos. Devido ao fato de a carta ${ }^{5}$ ser longa para ser apresentada neste artigo, disponibilizamos o link direto para que os leitores possam ter acesso a essa missiva.

No que tange às observações do céu, Christiaan pode identificar os anéis de Saturno e descobrir Titã, o maior satélite natural desse planeta. Além dos trabalhos de observação astronômica, Christiaan também foi um estudioso dos fenômenos e dos fundamentos da Ótica.

\footnotetext{
${ }^{5}$ Carta de Spinoza para Christiaan Huygens (05/1666). Disponível em: <http://ckcc.huygens.knaw.nl/epistolarium/letter.html?id=huyg003/1541>. Acesso em: 6 abr. 2016.
} 
Nesse campo, atuou como fabricante de lentes e construtor de poderosas lunetas para sua época. Estudou a reflexão e a refração e, ainda, propôs um modelo mecânico que tentava explicar a propagação da luz. Tal modelo foi considerado como um dos primórdios do modelo ondulatório estabelecido a partir do século XIX pelo fato de basear-se na transmissão de movimento entre partículas que compunham o éter (SILVA, 2007). Segundo Christiaan, a velocidade da luz era finita, contrariamente ao pregava Descartes. O modelo de Christiaan, entretanto, tinha forte influência da concepção mecanicista cartesiana:

\begin{abstract}
Huygens cresceu numa época em que o cartesianismo estava muito em voga. Seu pai era o diplomata e virtuoso Constantijn Huygens, um dos principais protetores de Descartes nas Províncias Unidas. Ele obteve como seu principal educador científico, o matemático Frans van Schooten, um grande amigo e admirador de Descartes. Ainda assim, sua relação com o cartesianismo permaneceu ambígua. Em sua juventude, Huygens ficou muito impressionado com o sistema de Descartes, mas, ao longo do tempo, ele veio a reconhecer várias deficiências nele, particularmente na sua Física. Huygens era muito de um matemático e muito pouco de um filósofo para se sentir verdadeiramente em casa no mundo cartesiano. Em vez disso, ele continuou a tradição de homens como Kepler e Galileu em sua descrição matemática da natureza. Se Descartes destinava a suplantar Aristóteles, Huygens figurou como um novo Arquimedes (VERMIJ, 2002, p. 148-149. Tradução livre dos autores).
\end{abstract}

Anton van Leeuwenhoek (1632-1723) foi um exímio construtor de lentes. Ele teve seus estudos financiados por Constantijn e foi apresentado por este à Royal Society. A partir desse ponto, passa a trocar cartas com várias personalidades: Henry Oldenburg (1619-1677), Robert Boyle (1627-1691), Robert Hooke (1635-1703) e com o astrônomo Christopher Wren (1632-1723). Na Holanda, Leeuwenhoek desenvolveu uma técnica de fabricação de lentes, utilizando não só o polimento, mas também o fogo como meio de moldar o vidro. Devido as suas novas técnicas, conseguiu construir as lentes mais potentes de sua época. Estima-se que os diversos modelos construídos por ele tinham ampliação que variava de 200 vezes a, possivelmente, 500 vezes. Há registro de pelo menos 25 microscópios por ele desenvolvidos. Desses, ainda existem 9 guardados em museus.

Leeuwenhoek não era um cientista nos padrões aceitos para aquela época. Sua obra experimental, contudo, foi bastante significativa para a futura Biologia. Seus interesses o ligavam aos seres vivos microscópicos que, nessa época, podiam ser percebidos com lentes que produziam imagens não muito nítidas. As lentes de Leeuwenhoek permitiram-lhe fazer grandes avanços nesse campo. Suas observações contribuíram para a Biologia Celular, descrevendo a estrutura celular dos vegetais, chamando as células de "glóbulos". Foi o primeiro a observar e descrever fibras musculares, bactérias, protozoários e o fluxo de sangue nos capilares sanguíneos de peixes.

Zuidervaart e Rijks (2015) fizeram uma pesquisa para encontrar indícios de estudos matemáticos e de ótica nos trabalhos de Anton van Leeuwenhoek e, com habilidade, os autores 
conseguiram fazer uma associação entre a academia militar situada em Delft e a produção de lentes. Nesse trabalho, também podemos encontrar um mapa mostrando a localização das residências de Leeuwenhoek, do pintor Johannes Verkolje (1650-1693), do topógrafo Jacob Spoors (1636-1650), do engenheiro e oftalmologista Johan van der Wyck (1623-1679), entre outros personagens que habitaram Delft e que tiveram papel importante nos estudos de ótica e na fabricação de lentes. Além de Verkoje, Vermeer era outro pintor que vivia a poucas quadras da casa de Leeuwenhoek e, possivelmente, compartilharam técnicas para o polimento de lentes.

\section{As lentes na pintura}

A utilização de instrumentos ópticos por pintores pode ser evidenciada em várias obras. David Hockney (2001), em seu livro O conhecimento secreto, procurou expor evidências visuais e documentais da utilização de instrumentos ópticos na Arte. Em primeiro lugar, mostra, por meio de alguns quadros, que, desde o século $\mathrm{XV}$, alguns instrumentos ópticos faziam parte do cotidiano dos europeus, sobretudo da região de Flanders (Fig. 3 e 4).

Nas Fig. 3 e 4, observamos algumas obras referidas no livro de Hockney (2001), tal como "O casamento de Arnolfini” (1434) (Fig. 3), pintado por Van Eyck (1390-1441), em que se pode perceber a existência de um espelho convexo ao fundo. Também podemos observar o mesmo espelho convexo em "The Werl Altarpiece” (1438) (Fig. 4), de Robert Campin (13751444).

No panorama holandês do século XVII, a pintura era uma atividade bastante difundida, as imagens proliferavam em toda parte. As imagens estavam presentes em livros, mapas, tapeçarias, toalhas de mesa, telhas, porcelanas.

A pintura holandesa, e em especial a obra de Vermeer, expressa, de forma bem clara, o ideal holandês de descrição da realidade tal qual era observada, contrariamente aos italianos, que pintavam uma natureza, muitas vezes, idealizada (ALPERS, 1999). Essa visão, em princípio de base empirista, fez com que aparelhos ópticos, como a câmara escura, fizessem parte do conjunto de instrumentos tanto dos laboratórios como dos ateliês de pintura.

Apesar de muitas técnicas de pinturas terem sido transmitidas somente entre alunos e mestres, que, normalmente, não as documentavam, a relação entre a câmara escura e seu uso na pintura pode ser encontrada no fragmento do texto de Karin Groen (2007), no qual é relatado que, para Constantijn Huygens, a obra "Emblematic Still Life with Flagon, Glass, Jug and Bridle", do pintor Jan Simonsz Torrentius, somente poderia ter sido feita com ajuda de um aparato mecânico. A pintura holandesa de gênero, também chamada de pintura descritiva, é a janela cultural de onde podemos ver um retrato da Holanda no século XVII. Tudo era motivo de descrição por meio da pintura, desde suas paisagens rurais, como nos quadros de Aelbert Cuyp (1620-1691), até suas cidades, como nas pinturas de Carel Fabritius (1622-1654). Seus habitantes e, sobretudo, os afazeres cotidianos de seus habitantes, serviam de inspiração a diversos pintores como Vermeer e Pieter de Hooch (1629-1684). Sabemos que vários desses pintores 


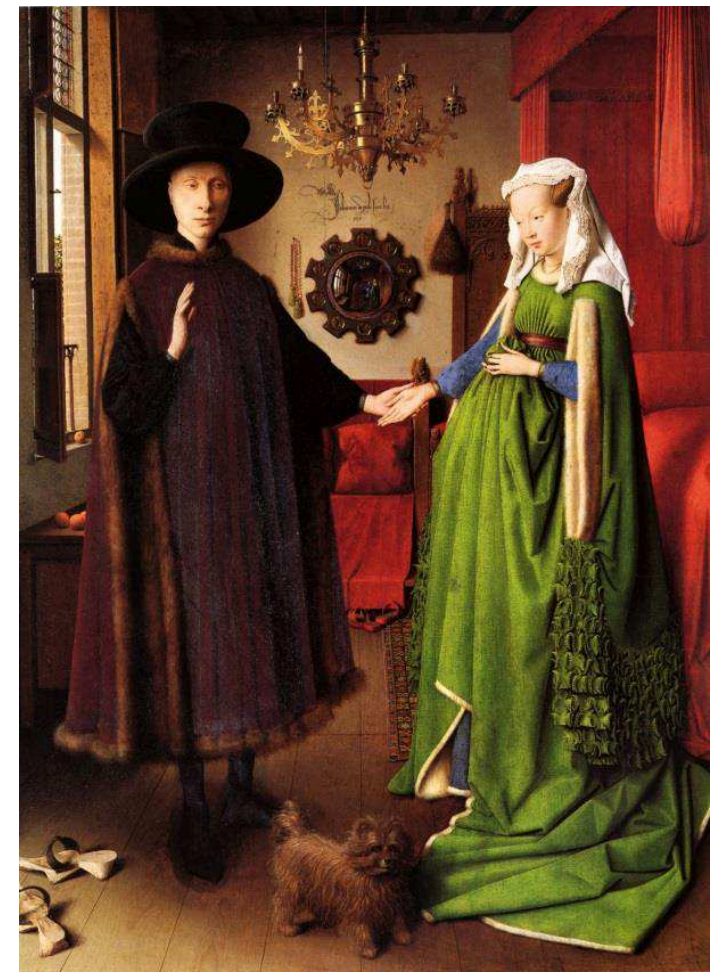

Fig. 3 - O casamento de Arnolfini (1434), pintado por Van Eyck. Fonte: Hockney, 2001.

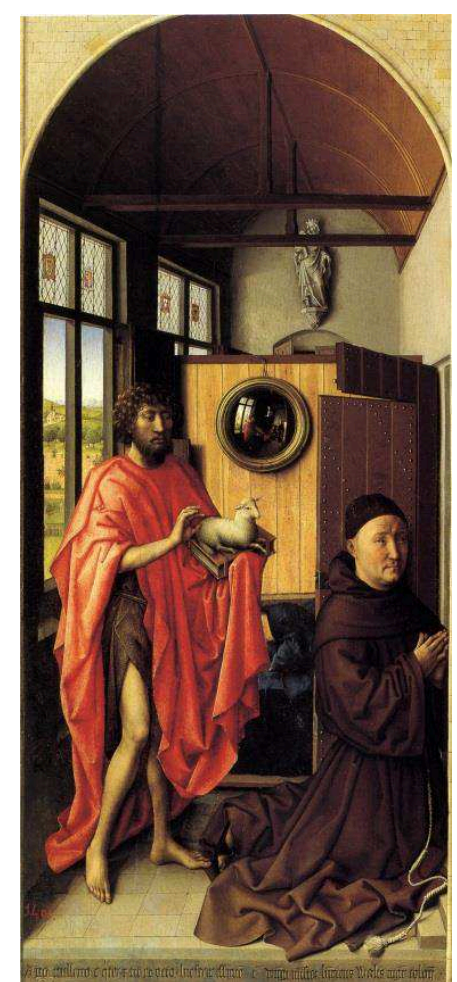

Fig. 4 - The Werl Altarpiece (1438), pintado por Robert Campin. Fonte: Hockney, 2001.

trocavam conhecimentos em sociedades como a "Gilde de São Lucas", em Delft. Assim, a partir dessas trocas, surgiram pinturas que podemos chamar de fotográficas, como aquela em que Vermeer apresenta “A Vista de Delft” (1660-1661) (Fig. 5).

A Vista de Delft é considerada um dos quadros que mais se aproximam de uma fotografia colorida, pintado no século XVII. Seu plano sem perspectiva sugere que este pode ter sido feito com o auxílio de lentes colocadas em uma câmara escura. Nas pinturas de Vermeer, objetos e pessoas são, na maioria das vezes, muito grandes. Algumas coisas são pintadas fora de foco ou com um foco suave, como no caso da obra "A leiteira" (1658-60) (Fig. 6).

Segundo Hockney (2001, p. 58), "Nesta pintura, a cesta em primeiro plano está fora de foco comparada à cesta pendurada ao fundo, uma distorção que Vermeer não teria visto a olho nu". Pode-se considerar essa evidência porque, ao direcionarmos a visão para um dado objeto, nosso sistema ocular tende a regular o foco, para deixar o objeto de interesse sem distorções visuais. Também não poderiam ter sido feitos os efeitos de "halo" dos realces fora de foco, vistos na cesta, no pão, no canecão e no jarro.

\footnotetext{
${ }^{6}$ Guildas são associações artesanais e/ou de ofícios, muito frequentes na Europa na Idade Média e assim permaneceram por um bom tempo. A Gilde de São Lucas de Delft foi uma das mais importantes associações de arte e ofícios do norte da Europa, no início da Europa Moderna.
} 


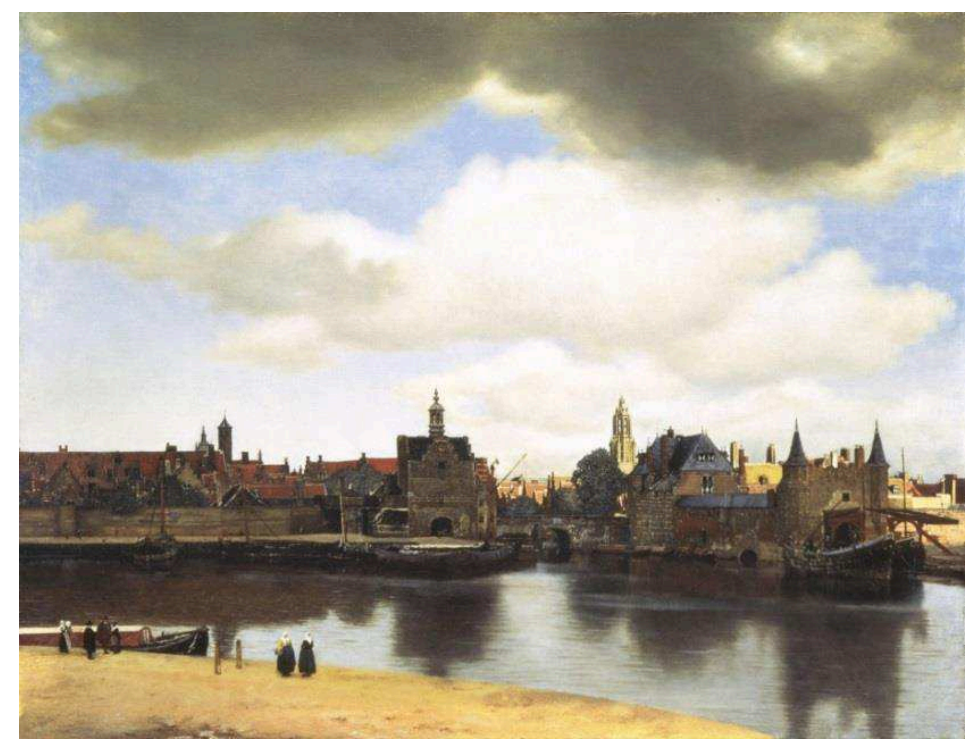

Fig. 5-A Vista de Delft (1660-1661). Fonte: Schneider, 2010.

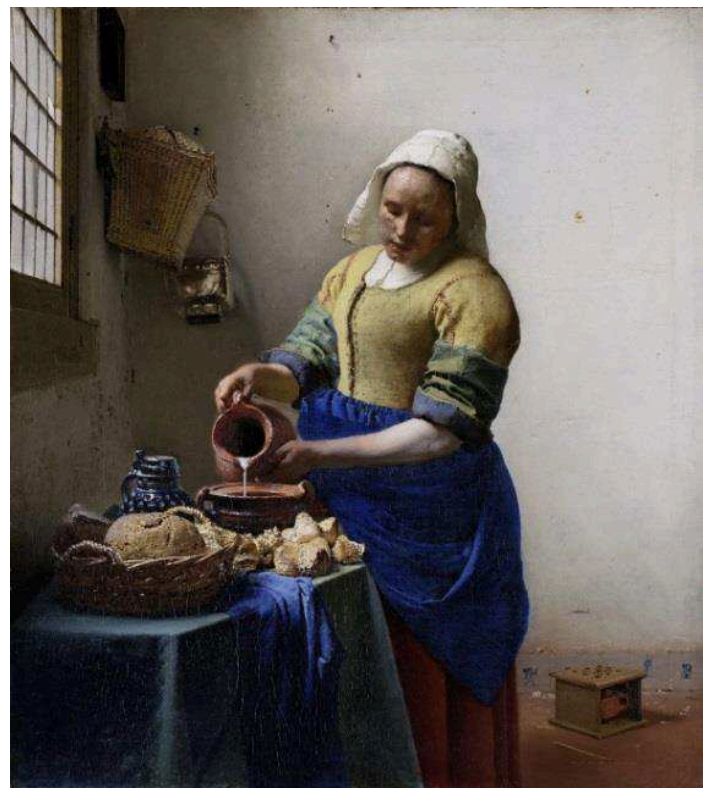

Fig. 6-A leiteira (1658-60). Fonte: Schneider, 2010.

Esse misto de engenho e habilidade produziu, na Holanda, a ilusão pictórica de vida. Os pintores holandeses foram, eminentemente, mais práticos do que teóricos (SNYDER, 2015, p. 90). Foi um pressuposto particular do século XVII o de achar e o fazer. "Nossa descoberta do mundo e nossa capacidade de representá-lo são presumivelmente uma coisa só". Esse pressuposto era comum ao projeto de invenção de uma linguagem universal, às experiências de Bacon em História Natural e à representação visual (ALPERS, 1999). 


\section{Os filósofos e as lentes}

O ideal artístico holandês de representação do real nas pinturas dialogava, de forma muito íntima, com o ideal científico inglês de um conhecimento tal qual fornecido pelos sentidos na interação homem-natureza. Esse tipo de pensamento poderia ser considerado uma versão artística daquilo que décadas mais tarde será chamado pela Filosofia de Empirismo, já no século XVIII. A ideia de que todo o conhecimento vem por meio dos sentidos e que só se pode confiar naquilo que vem por meio deles já existia em uma pintura que rompia com toda a tradição pictórica medieval e renascentista. A Arte do Renascimento italiano era baseada em uma visão idealizada do mundo, os corpos e as cenas eram concepções do belo. As lentes holandesas puderam trazer o mundo "real" para as telas, tal como se apresentava aos nossos olhos.

Por outro lado, pode-se afirmar, ainda, que o racionalismo cartesiano também possui fortes raízes holandesas. Constantijn Huygens foi, ao longo da maior parte do século XVII, uma das maiores referências culturais da Holanda. Ele mantinha um amplo círculo internacional de relações políticas e culturais, o que lhe permitia intermediar o mecenato tanto na Filosofia Natural como nas Artes sendo responsável pelo rápido crescimento da reputação da República holandesa (JARDINE, 2013, p. 31).

Em 1628, René Descartes viajou de Paris para a Holanda. Ele viveu em diversas cidades desse país até 1649. Durante esse período, conversou, pessoalmente, diversas vezes, com Constantijn e trocou cartas com ele durante os períodos em que esteve viajando, seja em diversas outras cidades holandesas por onde passou ou em viagens ao exterior. Algumas dessas cartas estão catalogadas em um trabalho publicado em 2003, pelo Departamento de Filosofia da Universidade de Utrecth (VERBEEK; BOS; VEM, 2003) e outras podem ser acessadas na plataforma ePistolarium.

No período holandês, Descartes publicou três pequenos tratados científicos: A Dióptrica, Os Meteoros e A Geometria. O prefácio dessas obras será, talvez, o maior e mais citado trabalho de Descartes: o Discurso sobre o método. Na Dióptrica, além de trabalhos teóricos, Descartes apresenta um estudo sobre as lentes e chegou a propor seu uso colado ao olho, como forma de correção dos defeitos da visão.

Baruch Spinoza (1632-1677) foi outro filósofo de importância que viveu no século de ouro da Holanda. Mesmo estando em um território de respeito às diferenças, Spinoza sofreu uma punição religiosa ao apresentar sua visão panteísta da natureza. A Sinagoga Portuguesa de Amsterdam puniu-o em 1656, com um "Chérem", algo equivalente à excomunhão, mas, de certa forma, mais severa, pois não poderia receber nenhum tipo ajuda financeira. Spinoza decidiu, então, sair de Amsterdam e seguir para Rijnsburg, perto de Haia, onde passou grande parte da sua vida. Mesmo recebendo convite de instituições de ensino, optou pelo trabalho filosófico e, assim, acabou fazendo do polimento de lentes sua fonte de renda. Possivelmente, Spinoza tenha conhecido Leeuwenhoek no verão de 1665, pois eles estavam separados somente por quatro milhas de distância; além disso, ambos trabalhavam no polimento de minúsculas lentes e tinham os membros da família Huygens como amigos (SNYDER, 2015, p. 112). Quando nos 
remetemos a um Spinoza artesão, devemos refletir que nossa Rede de Relações Sociais mostra uma relação direta entre o conhecimento acadêmico e o desenvolvimento da Ciência, mas esse fato também deixa, de forma clara, a importância do conhecimento técnico e artesanal. Esse conhecimento não acadêmico pode ser visto a partir dos "polidores de lentes", que eram indispensáveis para a construção dessas teorias (ZUIDERVAART; RIJKS, 2015).

\section{Conclusão}

O momento histórico referente ao texto remete ao interesse pela observação e pela medição da natureza, que exigiu novos instrumentos e novas formas de se observar (SNYDER, 2015, p. 5).

Para o Ensino de Ciências, sobretudo o ensino dos instrumentos ópticos, a câmara escura, o telescópio e o microscópio - elementos frequentes nos livros didáticos que abordam o estudo da ótica -, podem ser trabalhados sob outro ponto de vista que não seja somente tecnicista. Podemos discutir as propriedades dos espelhos e das lentes, descobrir quem compõe esses instrumentos, partindo do ponto para o qual eles foram desenvolvidos. E, remetendo à fala de Constantijn, buscar mostrar aos nossos alunos a importância deste "Novo Mundo", impossível de se ver a olho nu.

Traçar uma analogia entre o artista e o experimentador, entre o microscopista e o astrônomo, ou até mesmo entre o microscopista e o pintor, obriga-nos a lançar um novo olhar para a construção do conhecimento. O advento das lentes na Holanda do século XVII é um exemplo disso e pode ser utilizado em sala de aula para a construção de um currículo complexo.

Para esta pequena fração da rede, conseguimos identificar a figura de Constantijn Huygens como um $h u b$, em outras palavras, como um dos "conectores" que faziam com que a Rede Histórica holandesa do século XVII se desenvolvesse em vários aspectos: sociais, artísticos, econômicos, científicos, entre outros pontos que também poderíamos denominar Cultura ${ }^{7}$.

A busca do conhecimento natural no século XVII pode ser mostrada aos alunos, pois a ciência experimental baconiana pode ser vista, diretamente, nas pinturas holandesas. Essa analogia deve chegar à sala de aula, aproximando o conhecimento não só ao aluno, mas também aproximando o conhecimento entre disciplinas:

O impacto do telescópio, inventado em 1608, na nova cosmologia e filosofia natural está bem documentada. A influência deste instrumento na formação da teoria e outros dispositivos ópticos desenvolvidos mais tarde é bem conhecida e pode ser dificilmente subestimada. Instrumentos ópticos do século XVII podem ser o ponto de interseção das ciências matemáticas, físicas e técnicas (VERMIER apud ZUIDERVAART; RIJKS, 2015, p. 58. Tradução livre dos autores).

\footnotetext{
${ }^{7}$ Estamos nos referindo à visão de cultura de Edward Tylor: "Todo complexo que inclui conhecimento, crença, arte, moral, lei, costumes e outras aptidões e hábitos adquiridos pelo homem como membro da sociedade". (TYLOR apud BURKE, 2008, p. 43)
} 
O surgimento de linhas e disciplinas como Nanotecnologia, Bioengenharia, Etnobiologia, já são evidências de uma ciência nascente, mais conjuntiva e menos fragmentada (ALMEIDA, 2010, p. 28). A busca pela interdisciplinaridade já é recomendada pelos Parâmetros Curriculares Nacionais (PCNs). Contudo, enfrenta problemas quanto à inserção desse diálogo no cotidiano escolar. A preocupação em se discutir aspectos do desenvolvimento da Ciência também está presente em publicações internacionais há bastante tempo, tal como na obra Young People's Images of Science, de Driver et al. (1996, p. 84. Tradução livre dos autores): "Estudantes de todas as idades tendem a ver domínios científicos como a inclusão de fenômenos físicos e biológicos e excluindo fenômenos sociais".

Importa ressaltar, neste estudo, que não queremos abolir as especialidades, mas desejamos que as disciplinas escolares possam se agregar à construção de Redes Históricas como uma das ferramentas a ser utilizada na Educação em Ciências.

Como visto anteriormente neste estudo, estamos testando materiais educacionais com

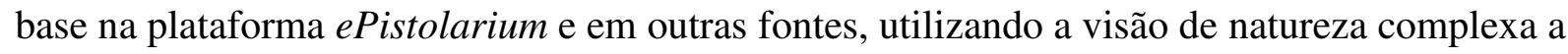
partir da montagem de Redes de Relações Sociais. A escolha por não os apresentar neste texto se deve a dois princípios: o primeiro tem como base divulgar e fundamentar o panorama teórico do episódio que escolhemos (os instumentos ópticos), e o segundo tem como base não deixar que um artigo de aplicação pareça um material acabado, como um roteiro para se trabalhar os instrumentos ópticos. Atuar na defesa teórica e na aplicação de forma substancial deixaria este trabalho, demasiadamente, longo para uma publicação em forma de artigo.

Entendemos que a montagem de Redes Históricas possui uma dinâmica que ultrapassa a rigidez dos livros didáticos. Se analisarmos a Figura 1, por exemplo, perceberemos que, ao final deste artigo, ela está ultrapassada. Vários outros personagens apareceram ao longo do texto. Por conseguinte, podemos concluir que a montagem de Redes Históricas pode contribuir para o Ensino de Ciências. Não é necessário mergulhar em cada personagem ou instrumento. Cabe ao professor definir qual o tamanho, a profundidade, o tempo didático e a temática para a qual dirigirá sua Rede de Relações Pessoais.

Na rede que escolhemos para este artigo, a câmara escura, o telescópio e o microscópio como atores não humanos ligados aos atores da Figura 1, em conjunto com o panorama histórico da Holanda nos séculos XVI e XVII, permite-nos discutir o advento dos instrumentos ópticos, tanto do ponto de vista do uso de novos instrumentos no trabalho científico, quanto para questões relacionadas ao eixo sociológico e histórico da Ciência (MARTINS, 2015).

No panorama do desenvolvimento dos instrumentos ópticos na Holanda, podemos fazer uma abordagem cultural da Ciência e esta poderá nos ajudar a compreendê-la melhor (ZANETIC, 1989). Muito mais do que isso, esse tipo de paralelo poderá ajudar a entender que a Ciência é um produto sociocultural e, como tal, deve ser apreendida (REIS; GUERRA; BRAGA, 2006). O caminho não é nada linear e podemos ver que cada fragmento pode falar por si mesmo. Ele pode até conter episódios lineares, podendo ou não ter características do todo. Já uma análise cartesiana desse episódio poderá distorcer a ideia dinâmica de um conhecimento 
que, de certa forma, não tem um começo nem um fim, mas é um corpo dotado de fatores que se comunicam, havendo uma compreensão de mundo que se "autoproduz" (MORIN, 1998).

\section{Referências}

ABRANTES, P. Imagens de Natureza, Imagens de Ciência. Campinas: Papirus, 1998.

AlCANTARA, M. C. História da Ciência, Filosofia e Arte na Holanda do século XVII: construindo um módulo para o ensino dos instrumentos ópticos. 2011. Dissertação (Mestrado em Ensino de Ciências e Matemática) - Centro Federal de Educação Tecnológica Celso Suckow da Fonseca, Rio de Janeiro, RJ, 2011.

; BRAGA, M. Panoramas de complexidade: história da Ciência, Filosofia e Arte na Holanda do século XVII. In: SEMINÁRIO NACIONAL DE HISTÓRIA DA CIÊNCIA E DA TECNOLOGIA, 12, 2010, Salvador. Proceedings...

ALLCHIN, D. Evaluating knowledge of the nature of (whole) science. Science \& Education, v. 95, p. 518-542, mar. 2011.

ALMEIDA, M. C. Complexidade, saberes científicos, saberes da tradição. São Paulo: Livraria da Física, 2010.

ALPERS, S. A arte de descrever. São Paulo: EDUSP, 1999.

ARAÚJO, L. C. Pintura de gênero holandesa do século XVII e Johannes Vermeer (2005).

Disponível em:

$<$ https://docs.google.com/viewer?a=v\&pid=sites\&srcid=ZGVmYXVsdGRvbWFpbnxsZW9sY2F8Z3g6NzEwMTA4N2QxZWIyM2JIMA>. Acesso em: 31 mar. 2016.

BARABASI, A. L. Linked: a nova ciência dos networks. São Paulo: Leopardo, 2009.

BRAGA, M. A nova paideia: Ciência e Educação na construção da modernidade. Rio de Janeiro: E-papers, 2000.

BRASIL. MEC. SEMTEC. Parâmetros Curriculares Nacionais para o Ensino Médio. Brasília: Secretaria de Educação Média e Tecnologia, 1999.

BURKE, P. Uma história social do conhecimento I: de Gutenberg a Diderot. Rio de Janeiro: Zahar, 2003.

O que é História Cultural? 2. ed. Rio de Janeiro: Zahar, 2008.

CAMEROTA, F. A Arte e Scienza: da Leonardo a Galileo. Firenze: Giunti, 2009. 
CHRISTAKIS, N. A.; FOWLER, J. H. O poder das conexões: connected. Rio de Janeiro: Elsevier, 2009.

DEMO, P. Complexidade e aprendizagem: a dinâmica não linear do conhecimento. São Paulo: Atlas, 2008.

DIJKSTERHUIS, F. J. Labour on lenses: Isaac Beeckman's notes on lens making”. In: VAN HELDEN et al. (Eds.). The Origins of the telescope. Amsterdam: KNAW, 2010. p. 257-270.

DRIVER, R. et al. Young People's Images of Science. Buckingham: Open University Press, 1996.

ELLiOTT, J. H. Europa en la época de Felipe II. 2. ed. Barcelona: Crítica, 2000.

FORATO, T. C. de M.; PIETROCOLA, M.; MARTINS, R. de A. Historiografia e natureza da Ciência na sala de aula. Caderno Brasileiro de Ensino de Física, Florianópolis, v. 28, n. 1, p. 27-59, jan. 2011.

GROEN, K. Painting Technique in the Seventeenth Century in Holland and the Possible Use of the Camera Obscura by Vermeer. In. LEFÈVRE, W. (Ed.). Inside the Camera Obscura: Optics and Art under the Spell of the Projected Image. Berlim: Max-Planck-Institut für Wissenschaftsgeschichte, 2007.

GUERRA, A.; REIS, J. C.; BRAGA, M. A. B. Uma abordagem histórico-filosófica para o eletromagnetismo no Ensino Médio. Caderno Brasileiro de Ensino de Física, Florianópolis, v. 21, n. 2, p. 224-248, jan. 2004.

HENKE, A.; HÖTTECKE, D. Physics Teachers' Challenges in Using History and Philosophy of Science in Teaching. Science \& Education, v. 24, p. 349-385, May, 2015.

HOCKNEY, D. O conhecimento secreto. São Paulo: Cosac \& Naify, 2001.

HÖTTECKE, D.; SILVA, C. C. Why implementing history and philosophy in school science education is a challenge. An analysis of obstacles. Science \& Education, v. 20, p. 293-316, Mar. 2011.

JARDINE, L. Going Dutch: how England plundered Holland's glory. New York: Haper Collins, 2008.

De Familie Huygens: En de Engels Nederlandse betrekkingen. In: LEERINTVELT, Ad et al. Constantijn \& Christiaan Huygens: Een gouden erfenis. Eindhoven: Lecturis, 2013. p. 29-44.

LATOUR, B. Ciência em ação: como seguir cientistas e engenheiros sociedade afora. São Paulo: Editora da UNESP, 1997. 
LEE, S. J. A Guerra dos Trinta Anos. São Paulo: Ática, 1994.

LEERINTVELD, Ad; PLOEG, P. Het leven van Constantijn Huygens: Voor vaderland en Oranje. In: LEERINTVELD, Ad et al. Constantijn \& Christiaan Huygens: Een gouden erfenis. Eindhoven: Lecturis, 2013. p. 45-108.

LEMIEUX, V.; OUIMET, M. Análise Estrutural das Redes Sociais. 2. ed. Lisboa: Instituto Piaget, 2012.

MARIOTTI, H. Pensamento Complexo: suas aplicações à liderança, à aprendizagem e ao desenvolvimento sustentável. São Paulo: Atlas, 2007.

MARTINS, A. F. P. Natureza da Ciência no Ensino de Ciências: uma proposta baseada em "temas" e "questões". Caderno Brasileiro de Ensino de Física, Florianópolis, v. 32, n. 3, p. 703-737, maio, 2015.

MATTHEWS, M. History, Philosophy, and Science Teaching: The Present Rapprochement. Science \& Education, Kluwer, v. 1, p. 11-47, 1992.

. Teaching the Philosophical and Worldview Components of Science. Science \& Education, Kluwer, v. 18, p. 697-728, 2009.

MORIN, E. O problema epistemológico da Complexidade. Lisboa, Portugal: Europa-América, 1993.

. “Complexidade e liberdade”. Ensaios THOT, Associação Palas Athena, São Paulo, n. 67, p. 12-19, 1998.

Introdução ao Pensamento Complexo. Porto Alegre: Meridional/Sulina, 2005.

PERON, T. S.; ALCANTARA, M. C.; JARDIM, W. T. The inclusion of HPS in the Physics course curriculums for pre service teachers of Brazilian Universities. In: 13TH IHPST BIENNIAL CONFERENCE, 2015, Rio de Janeiro. Proceedings... v. 1. 2015.

PRIGOGINE, I.; STENGERS, I. A nova aliança. Brasília: UNB, 1984.

REIS et al. History, Science and Culture: Curricular Experiences in Brazil. Science \& Education, v. 10, p. 369-378, Mar. 2011.

REIS, J. C.; GUERRA, A.; BRAGA, M. Science and art: unlikely relations? História, Ciências, Saúde, Manguinhos, v. 13, p. 71-87, Oct. 2006. Supplement.

SCHAMA, S. O desconforto da riqueza: a cultura holandesa na época de ouro. São Paulo: Companhia das Letras, 1992.

SCHNEIDER, N. Vermeer (1632-1675): emoções veladas. Colonia: TASCHEN, 2010. 
SILVA, F. W. O. A evolução da Teoria Ondulatória da Luz e os livros didáticos. Revista Brasileira de Ensino de Física, v. 29, n. 1, p. 149-159, 2007.

SNYDER, L. J. Eye of the Beholder. New York: W. W. Norton \& Company Ltda, 2015.

SNOW, C. P. As duas culturas e uma segunda leitura. São Paulo: Universidade de São Paulo, EDUSP, 1995.

STEADMAN, P. Vermeer's Camera: Uncovering the Truth Behind the Masterpieces. New York: Oxford University, 2001.

TAVARES. F., T.; PRESTES, Maria E. B. Pseudo-história e ensino de Ciências: o caso Robert Hooke. Revista da Biologia, v. 9, p. 35-42, dez. 2012.

VAN DEN HEUVEL, C. Mapping Knowledge exchange in Early Modern Europe intellectual and technological geographies and network representations. International Journal of Humanities and Arts Computing, v. 9, n. 1, p. 95-114, 2015.

VERBEEK, T.; BOS, E.; VEM, J. V. The correspondence of René Descartes 1643: Publications of the Department of Philosophy. Holanda: Utrecht University, 2003.

VERMIJ, R. The Calvinist Copernicans: the reception of the new astronomy in the Dutch Republic, 1575-1750. Royal Netherlands Academy of Arts and Sciences. Amsterdam: KNAW, 2002.

The telescope at the court of the stadtholder Maurits. In: VAN HELDEN et al. (Eds.). The Origins of the telescope. Amsterdam: KNAW, 2010. p. 73-92.

WATTS. D. Seis graus de separação: a evolução da Ciência em uma era conectada. São Paulo: Leopardo, 2009.

ZANETIC, J. Física também é cultura. 1989. Tese (Doutorado em Educação) - Faculdade de Educação da Universidade de São Paulo, Universidade de São Paulo, São Paulo, 1989.

ZUIDERVAART, H. J. The "true inventor" of telescope. In: VAN HELDEN et al. (Eds.). The Origins of the telescope. Amsterdam: KNAW, 2010. p. 9-44.

; RIJKS, M. Most rare workmen: optical practitioners in early seventeenth-century Delft. The British Journal for the History of Science, v. 48, p. 53-85, 2015. 